\title{
Diagnostic evaluation of pancytopenia - a prospective institutional study in North-East India
}

\author{
Datta $\mathrm{A}^{1}$, Banerjee $\mathrm{A}^{2}$, Dasgupta $\mathrm{A}^{3}$, Debbarma SK ${ }^{4}$, Nath $\mathrm{D}^{5}$ \\ ${ }^{1}$ Dr Abhijit Datta, Associate Professor, Department of Pathology, ${ }^{2}$ Dr Alpana Banerjee, Assistant Professor, Department \\ of Pathology, ${ }^{3}$ Dr Arunabha Dasgupta, Associated Professor, Department of Medicine, ${ }^{4}$ Dr Sanjib Kr. Debbarma, \\ Associate Professor, Department of Pediatrics, ${ }^{5}$ Dr Debashis Nath, Medical Officer, Department of Medicine; first 4 \\ authors are affiliated with Agartala Goverment Medical College \& GB Pant Hospital, Kunjaban, Agartala, Tripura, India \\ and $5^{\text {th }}$ author with Indira Gandhi Memorial Hospital, Government of Tripura, Agartala, Tripura, India.
}

Address for Correspondence: Dr. Abhijit Datta, Associate Professor, Department of Pathology, Agartala Government Medical College \& GB Pant Hospital, PO - Kunjaban, Agartala, Tripura. Email id: abhijitpath62@gmail.com

\begin{abstract}
Introduction: Pancytopenia, the simultaneous reduction of all the three formed elements of blood, is diverse in its etiology. Full clinico-hematopathological work up is crucial in each case. This study was undertaken with the objectives of identifying the causes of pancytopenia and its phenotypic characteristics in relation to age, sex, ethnicity and socioeconomic status. Methods: Ninety two cases of pancytopenia studied here were diagnosed by complete hemogram study in automated hematology analyzer. Peripheral blood smear studies were carried out. All cases were subjected to bone marrow aspiration/ imprint smear cytology and trephine biopsy study. Hypoplastic anemia cases were investigated for paroxysmal nocturnal hemoglobinuria $(P N H)$ with flow cytometric analysis of red blood cells treated with CD55 and CD59 antibodies. Results: Fifty eight percent of cases were males and mean age was 52 years. Children constituted 16\% of patients. Thirty-seven percent of cases belonged to tribal community. Around $70 \%$ belonged to low socio-economic status. Causes of pancytopenia detected were primary hematological malignancies (Total $39.2 \%$ with acute leukaemia $35.9 \%$, lymphoma $2.2 \%$ and multiple myeloma $1.1 \%$ ), hypoplastic anaemia (28.3\%), myelodysplastic syndrome (MDS) (21.7\%), megaloblastic Anemia (6.5\%) and hypersplenism (4.3\%). No PNH clone was detected amongst hypoplastic anemia cases. Conclusion: It is concluded that pancytopenia often is the manifestation of serious disease-processes and the commonest cause, in our population of this North-Eastern state of Tripura, being acute leukemia. Bone marrow cytology and biopsy study must be performed in all cases of pancytopenia to find out the cause in order to institute an early treatment.
\end{abstract}

Key words: Bone marrow trephine biopsy, Complete hemogram, Hypoplastic anemia, Megaloblastic anemia, Pancytopenia

\section{Introduction}

Pancytopenia is a clinicopathological condition characterized by simultaneous presence of anemia, leucopenia and thrombocytopenia. A variety of diseases can result in this triad of features, namely aplastic anemia, subleukemic leukemia, cytotoxic drugs, radiotherapy, myelodysplastic syndromes, myelopthisis, hypersplenism, megaloblastic anemia, collagen vascular diseases, paroxysmal nocturnal hemglobinuria (PNH),

Manuscript received $20^{\text {th }}$ August 2016

Reviewed: $4^{\text {th }}$ September 2016

Author Corrected: $15^{\text {th }}$ September 2016

Accepted for Publication $29^{\text {th }}$ September 2016 disseminated severe infection etc $[1,2]$. A total hematopathological work up is essential to find out the etiology of pancytopenia to plan case wise proper therapeutic strategies [3]. Thus performing a complete blood count (CBC), bone marrow aspiration/ imprint cytology and bone marrow trephine biopsy are very vital in the overall management of the pancytopenic patients [4]. In order to reach the final diagnosis sometimes immunophenotyping, cytogenetic analysis and molecular genetic studies etc. are required in addition to findings of $\mathrm{CBC}$, bone marrow cytology and 
trephine biopsy [1]. Although a good number of cases of pancytopenia are encountered in day to day clinical practice, the available studies on causes of pancytopenia from India, eastern region of India in particular, are limited [3, 5, 6, 7]. Moreover, to our knowledge the number of detail studies on pancytopenia from North East India is extremely meager [8,9]. The present hospital based study was undertaken to find out the prevailing causes of pancytopenia and its phenotypic characteristics in relation to age, sex, ethnicity and socio- economic status in this region of the country with a mixed tribal and non-tribal population.

\section{Materials \& Methods}

It was a prospective study of two years duration conducted at Agartala, Tripura, India during April 2013 to March 2015, by the Department. of Pathology in collaboration with Departments of Medicine and Paediatrics, Agartala Govt. Medical College \& GB Pant Hospita and Department of Medicine, Indira Gandhi Memorial Hospital, Agartala. Ethical approval was obtained from the Institutional Ethics Committee, Agartala Govt. Medical Collge.

A total of 92 cases of pancytopenia irrespective of age, sex, ethnicity \& socio-economic status were included in the study. Patients having coagulation disorders and patients on chemo and/ or radiotherapy were excluded.

After taking an informed consent, a detail history, thorough clinical examination and peripheral blood examination (complete haemogram and reticulocyte count) of all study subjects were carried out. Complete haemograms were done by using automated blood cell counter (with three parts differentials facility; Sysmex Corpn., Japan; model- XP-100) and peripheral smears were studied along with. This facilitated the identification of pancytopenia cases. For complete haemogram study $2 \mathrm{ml}$ of blood sample was collected in EDTA-tube and the sample was run in autoanalyzer. The results of most of the various parameters namely hemoglobin, hematocrit value, RBC count, platelet count, total leucocyte count, differential leucocyte count, $\mathrm{MCV}, \mathrm{MCH}$, and $\mathrm{MCHC}$ were verified with findings in peripheral smear stained with Giemsa's stain. The peripheral smears were examined by using a binocular light microscope (Olympus, CX 21).

For Reticulocyte (Retic) count $500 \mu \mathrm{l}$ of whole blood was directly mixed with equal volume of supra-vital stain namely Brilliant Cresyl Blue and then incubated at
$37^{0} \mathrm{C}$ for 5 minutes. Then smear was made from that post-incubated sample and reticulocyte count in percentage of red cells was found out following standard guidelines [10].

All the ninety two (92) cases of pancytopenia underwent bone marrow (BM) trephine biopsy with use of Jamshidi needle. For adult patients needles of $11 \mathrm{G}$ and $8 \mathrm{G}$ sizes were used, whereas for pediatric patients needles of $13 \mathrm{G}$ size were used. The site for bone marrow biopsy was posterior superior iliac spine. After preparing the patients with local anesthesia by local infiltration of Lignocaine injection (2\%) upto periosteum and sterilizing the area with antiseptics and with all other aseptic precautions, percutaneous trephine biopsy of bone marrow was performed from posterior superior iliac spine. Imprint smears were prepared by gently rolling the marrow biopsy specimen on glass slides. Four smears were prepared - two were stained with Giemsa's stain with standard protocol for cytological evaluation, one with Perls'stain for iron status assessment [10]. One smear was preserved for future use in case required. In most of the cases during the biopsy procedure bone marrow aspiration was also performed just prior to taking the biopsy. Biopsy specimens were processed and stained as per standard protocol [11]. These were fixed in 10\% neutral buffered formalin for a minimum of 4 hours followed by decalcification using fresh aqueous nitric acid (5\%). After tissue processing with passing through steps of dehydration, clearing and impregnation followed by embedding into paraffin wax block, less than $4 \mu \mathrm{m}$ thick sections were cut and stained with Hematoxylin and Eosin (HE) stain and were examined by binocular light microscope with assessment of cellularity, cell distribution and location alongwith cell morphology, fibrosis and presence of abnormal cells. Bone marrow biopsy findings were correlated with bone marrow imprint/ aspiration smear cytology and vice versa to reach into a final diagnosis.

Blood samples of all hypoplastic anaemia cases as diagnosed by BM biopsy study were subjected to flow cytometric analysis for immunophenotyping of red blood cells for CD55 and CD59 to rule out PNH. Flow cytometric analysis of red cells was performed in blood samples of 26 hypoplastic anemia patients by direct immunofluorescence using monoclonal anti-CD55 and anti-CD59 antibodies (BD Biosciences). The protocol followed for flow cytometric analysis was briefly as follows : $10 \mu \mathrm{l}$ of whole blood diluted in $2 \mathrm{ml}$ of phosphate buffer solution (PBS) and then $20 \mu \mathrm{l}$ of 
diluted blood was taken in a fresh tube to which $20 \mu \mathrm{l}$ of antibody (CD55/ CD59) was added with thorough mixing. Then it was incubated for 30 minutes at room temperature in dark. (For unstained samples instead of antibody, $20 \mu \mathrm{l}$ of PBS was used). After incubation 0.5 $\mathrm{ml}$ of PBS was added and then the sample tube was run in flow cytometer (BD Biosciences, model : FACS Canto-II).

Descriptive statistics was carried out using SPSS software.

\section{Results}

Out of a total (n) of 92 cases $53(58 \%)$ were males and 39 (42\%) were females. Fifteen cases (16\%) were children (below 14 years) and $77(84 \%)$ cases were adults (mean age 56 years). Thirty four cases (37\%) belonged to local tribal community of Tripura and rest $58(63 \%)$ were Bengalis. Out of 92 cases $64(69.5 \%)$ belonged to low socio-economic status and rest $28(30.5 \%)$ belonged to middle class socio-economic group.

Results of important parameters on peripheral blood examination are given in Table-1. Bone marrow iron store was found to be increased (grade : 4-5) in hypoplastic anemia, acute leukaemias and hypersplenism cases and in rest of the cases the iron store was found to be within normal limit (grade : 2-3). CD55 and CD59 expression was normal in all cases of hypoplastic anemia; therefore no PNH clone was detected. Different causes/ final diagnoses of pancytopenia as found on bone marrow study are given in Table- 2 .

Table 1: Results of important parameters on peripheral blood examination $(n=92)$.

\begin{tabular}{|c|c|c|c|}
\hline Parameters & Mean & Range & Normal Ref. Range of Lab. \\
\hline Hemoglobin (gm/dl) & 6.9 & $4.6-9.8$ & Males:14.5 $\pm 2 ;$ Females:13 \pm 2 \\
\hline $\operatorname{HCT}(\%)$ & 21.8 & $13.9-31.4$ & Males:45 $\pm 7 ;$ Females:40 \pm 6 \\
\hline Total leucocyte count $(/ \mu \mathrm{l})$ & 2,657 & $1,842-3,668$ & $4,000-11,000$ \\
\hline RBC count (millions/ $\mu \mathrm{l})$ & 2.9 & $2.2-4.1$ & Males:5.5 $\pm 1 ;$ Females:4.8 \pm 1 \\
\hline Platelet count $(/ \mu \mathrm{l})$ & 66,234 & $14,320-120,880$ & $150,000-400,000$ \\
\hline MCV (fL) & 86.7 & $75.4-122.8$ & $85 \pm 9$ \\
\hline $\mathrm{MCH}(\mathrm{pg})$ & 28.9 & $22.3-32.2$ & $29 \pm 3$ \\
\hline $\mathrm{MCHC}(\mathrm{g} / \mathrm{dl})$. & 34.3 & $29.7-36.6$ & $34 \pm 2$ \\
\hline Reticulocyte count (\%) & 0.4 & $0.1-2.6$ & $0.2-2$ \\
\hline
\end{tabular}

Table 2: Causes of Pancytopenia as diagnosed after bone marrow study.

\begin{tabular}{|c|c|c|}
\hline Causes responsible for pancytopenia & No. of Cases $(n=92)$ & Percentage (\%) of Total \\
\hline $\begin{array}{c}\text { Primary bone marrow/ hematological } \\
\text { malignancies : Acute Leukaemia, Non- } \\
\text { Hodgkin's lymphoma (NHL) \& Multiple } \\
\text { Myeloma (MM) }\end{array}$ & $\begin{array}{c}36 \\
(\text { Acute Leukaemia } 33+\text { NHL } 2 \\
+ \text { MM 1) }\end{array}$ & $\begin{array}{c}39.2 \\
(\text { Leukaemia } 35.9 \%+\text { NHL } 2.2 \% \\
+ \text { MM } 1.1 \%)\end{array}$ \\
\hline Hypoplastic anaemia & 26 & 28.3 \\
\hline Myelodysplastic syndrome (MDS) & 20 & 21.7 \\
\hline Megaloblastic Anemia & 6 & 6.5 \\
\hline Hypersplenism & 4 & 4.3 \\
\hline
\end{tabular}

Among the total number of 33 acute leukaemia cases 29 were found to be acute myeloid leukaemias (AML) and 4 were acute lymphoblastic leukaemias (ALL). 


\section{Discussion}

The causes of pancytopenia are diverse in different population or geographical areas. According to various studies from different parts of the world including some parts of India the commonest underlying cause of pancytopenia is hypoplastic anemia and its frequency varies from $10 \%$ to over $50 \%$ [4, 7, 8, 12-15]. Our experience in this study is different. We have found primary bone marrow / hematological malignancies (leukemia, lymphoma \& MM) to be the most common cause of pancytopenia $(39.1 \%$ ) in this state (Tripura) of North East India. This experience is even different from that of Raphael, Khonglah and Dey et al. who found megaloblastic anemia to be the commonest etiology (41.2\%) of pancytopenia in the state of Meghalaya, another nearby north-eastern state mostly tribal inhabited [9]. In their study at Davangere in Karnataka, Gayathri and Rao also found megaloblastic anemia had been the commonest cause (74\% cases) of pancytopenia [3]. But in a study in another north-eastern state, Manipur the investigators found that hypoplastic anemia had been the most common cause (22\%) followed by megaloblastic anemia and myelodysplastic syndrome (18\% each $)^{8}$. In our study megaloblastic anemia constituted only $6.5 \%$ cases, which is quite less in comparison to aforesaid studies. Incidence of megaloblastic anemia in this state is less probably because of the non-vegetarian dietary habits of the nearly $100 \%$ population here.

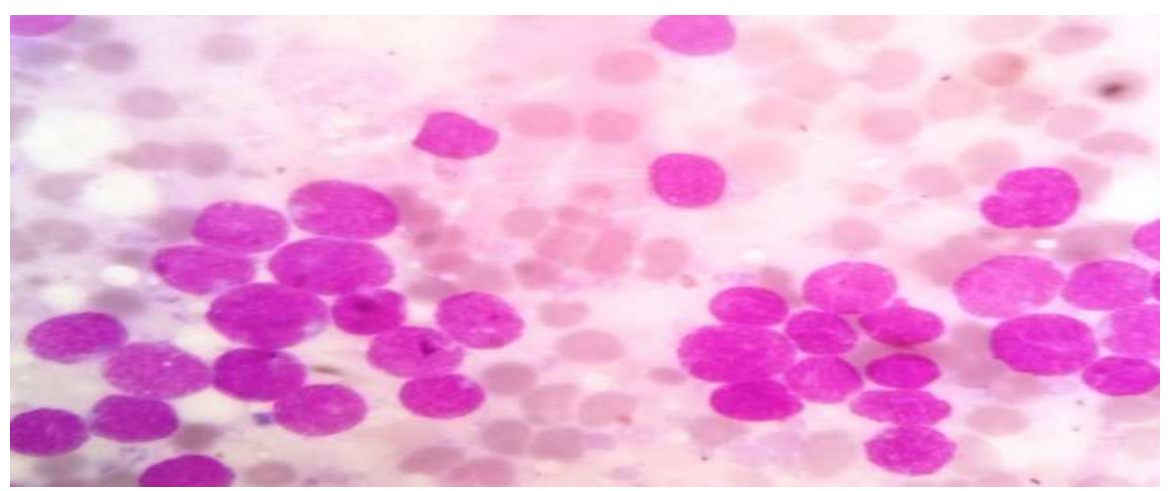

Figure-1: Photomicrograph of bone marrow imprint smear from a child with acute lymphoblastic leukaemia (ALL). Giemsa, x1000.

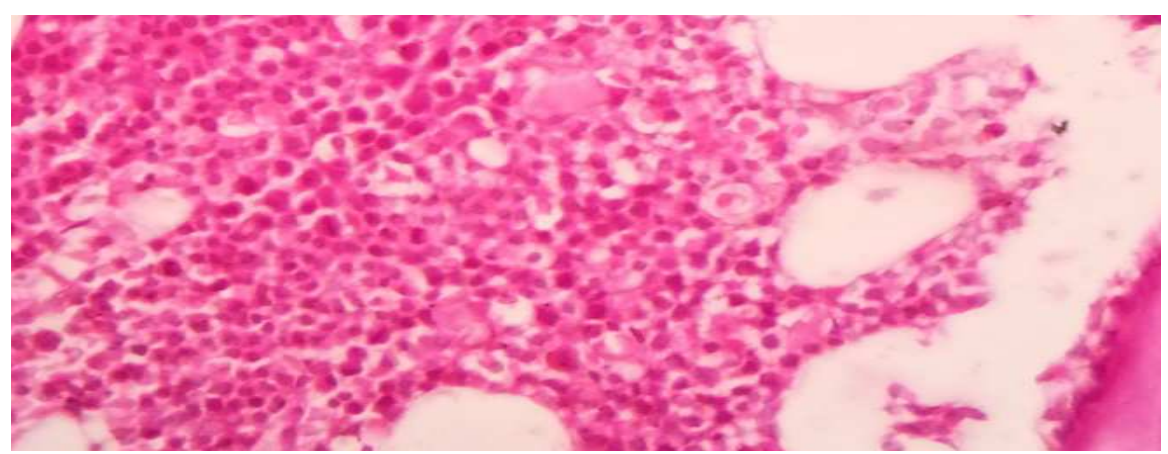

Figure-2: Photomicrograph of bone marrow biopsy section of the above case of ALL. HE, $x 400$

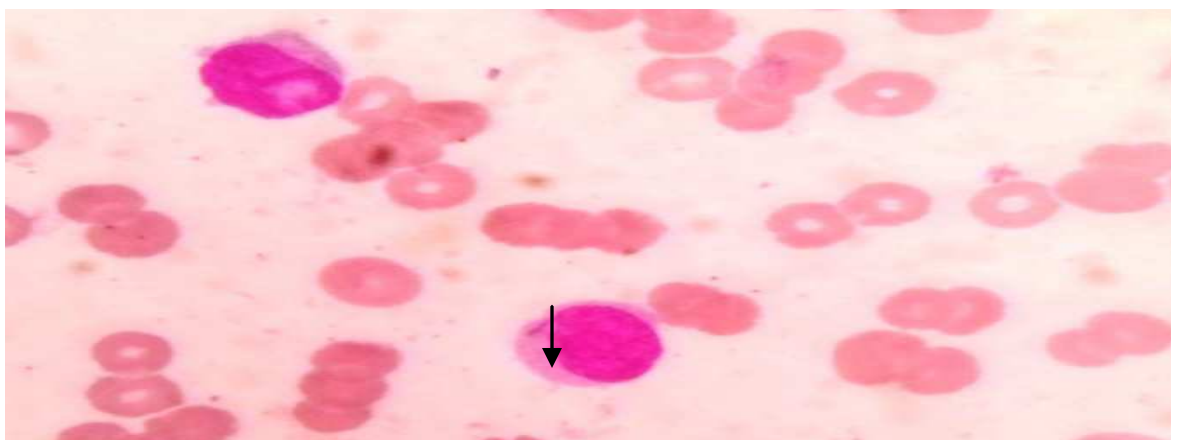

Figure-3: Photomicrograph of peripheral smear from a case of AML showing a myeloblast with Auer rod (arrow). Giemsa, x1000. 


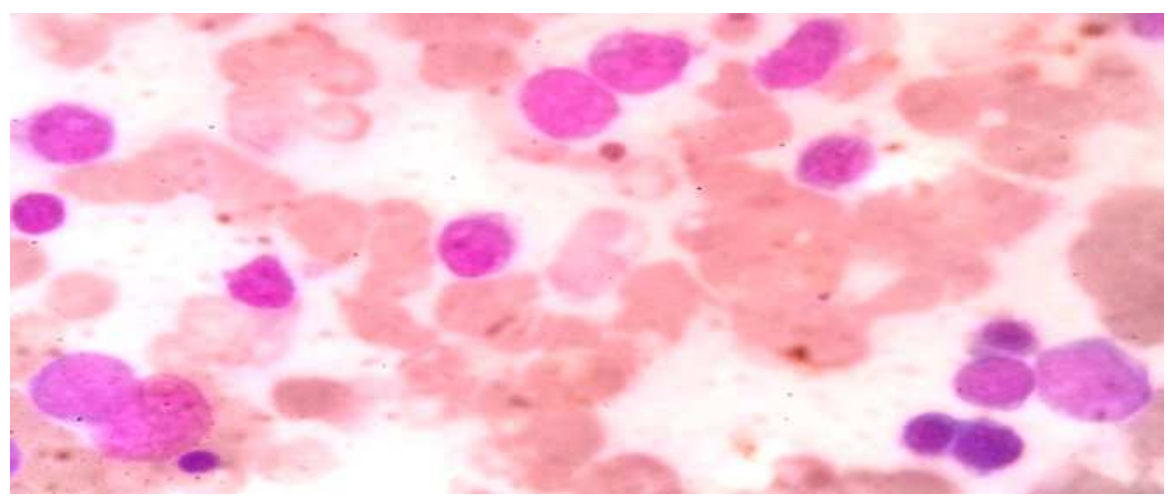

Figure-4: Photomicrograph of bone marrow imprint smear from a case of acute myeloid leukemia (AML). Giemsa, x1000

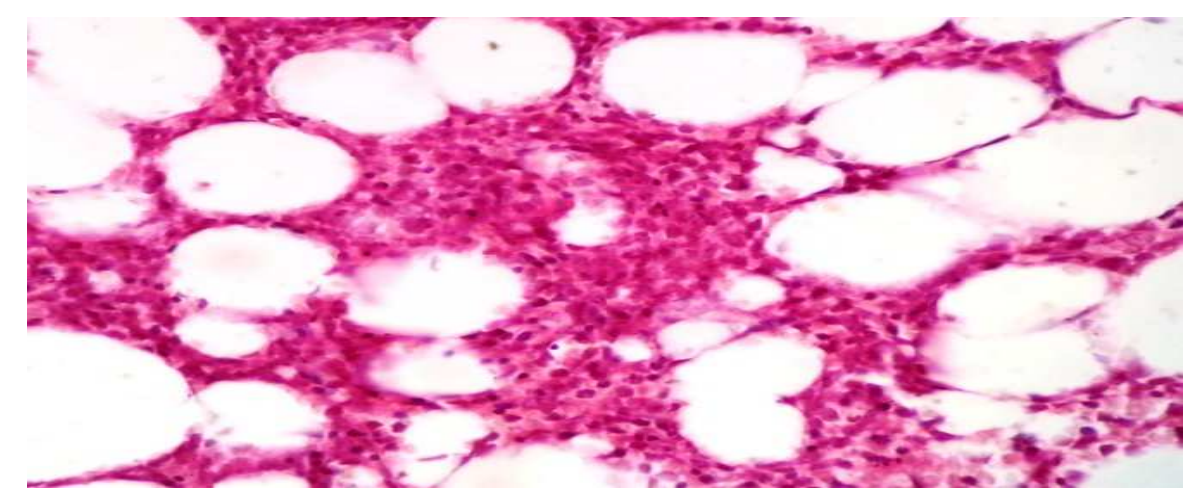

Figure-5: Photomicrograph of bone marrow biopsy from a case of acute myeloid leukemia (AML). HE, x400.

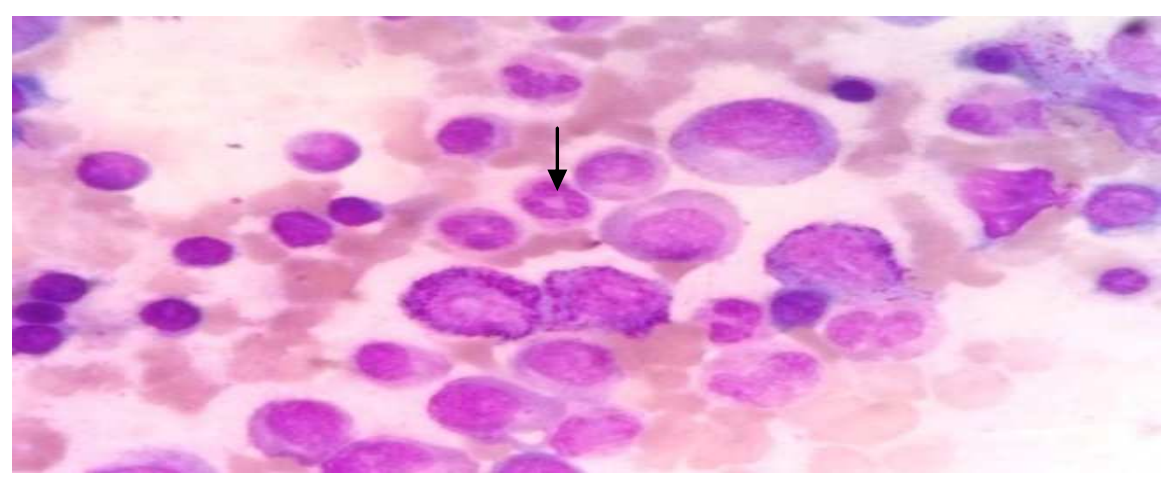

Figure-6: Photomicrograph of bone marrow aspiration smear from a case of MDS showing ring nucleus of neutrophil (arrow). Giemsa, x1000.

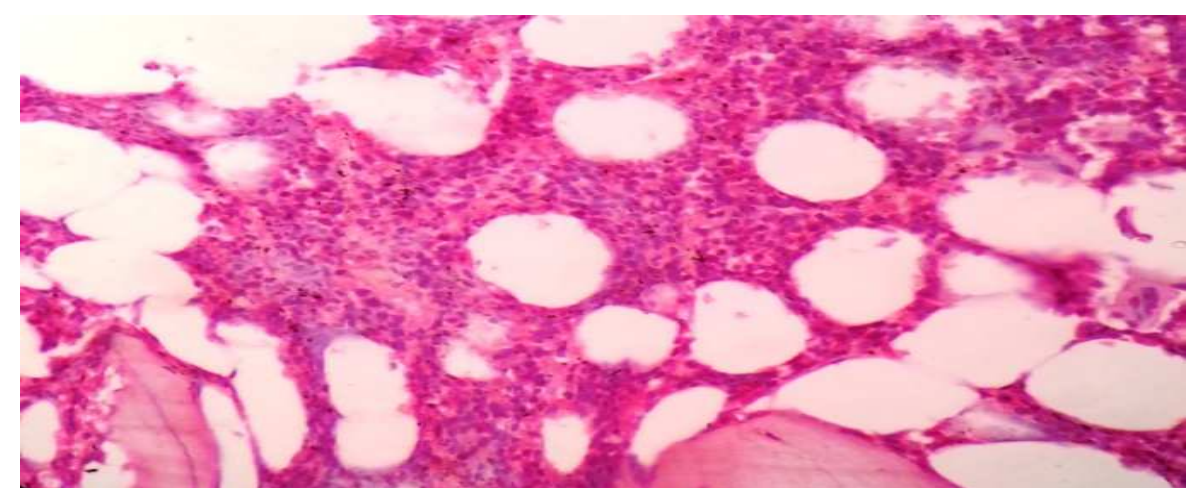

Figure 7: Photomicrograph of bone marrow biopsy from a case of MDS. HE, x400. 


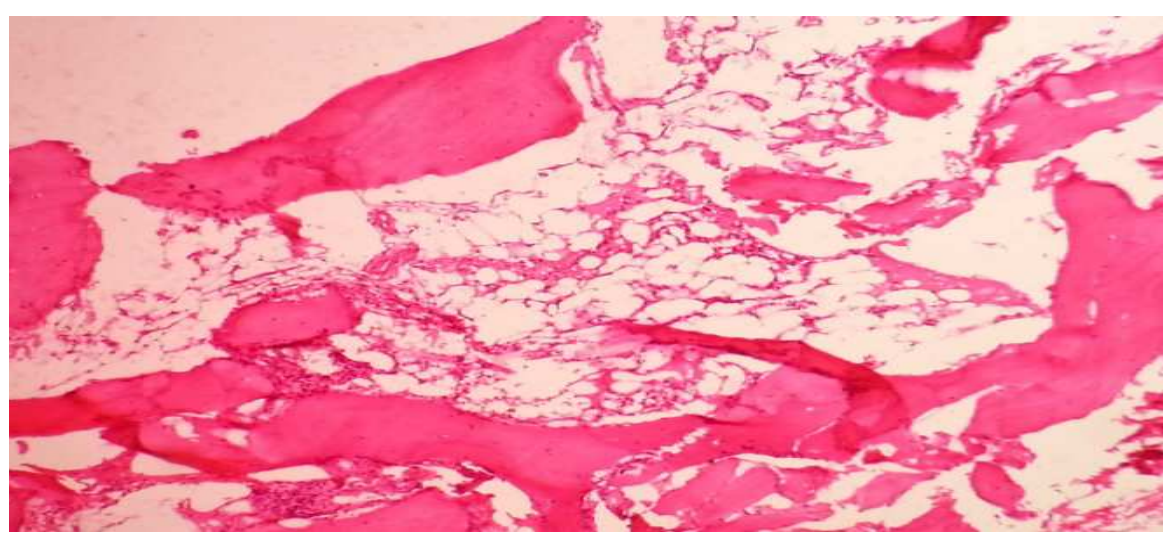

Figure-8: Photomicrograph of bone marrow biopsy from a case of hypoplastic anemia. HE, x100

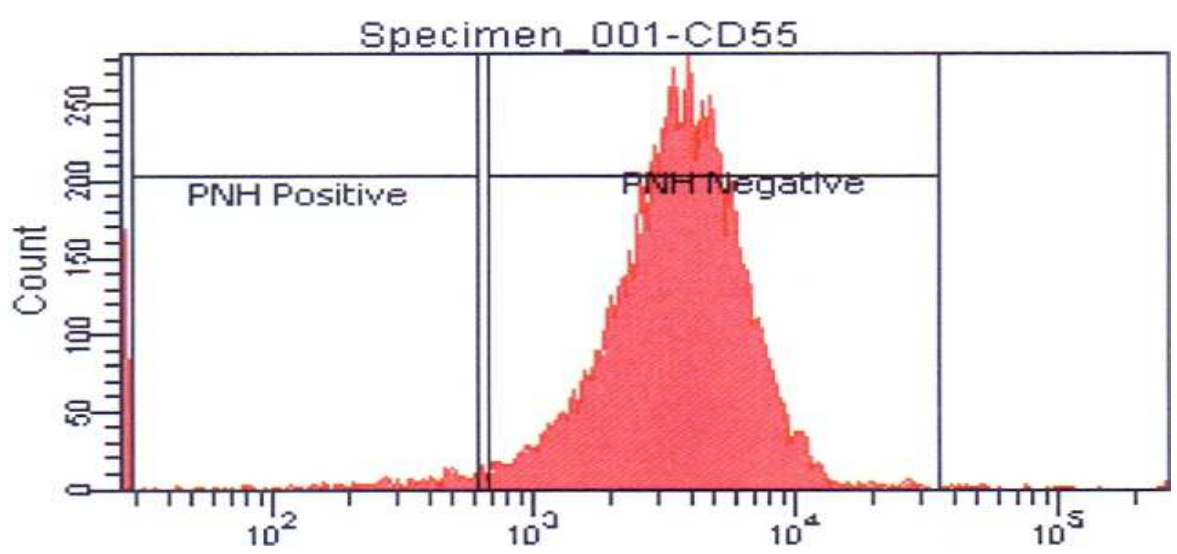

Figure-9 : Flowcytometric histogram as obtained with anti-CD55 treated sample in a case of hypoplastic anemia. (Normal expression).

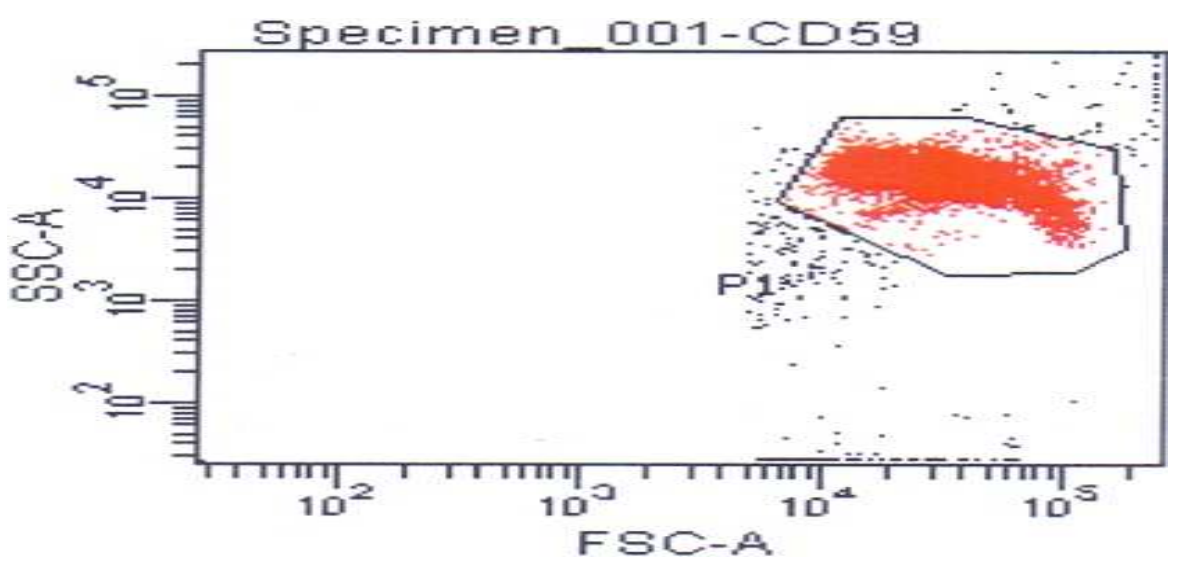

Figure 10: Flowcytometric density plot as obtained with anti-CD59 treated sample in a case of hypoplastic anemia (Normal expression).

Frequency of primary hematological malignancies like leukemia, lymphoma, multiple myeloma etc. constituted a substantial proportion of nearly $40 \%$ of pancytopenic patients in our study. Few other studies in India and its neighbouring countries like Nepal and Pakistan also primary hematological malignancies were observed in a considerable proportion of pancytopenia cases although these were not the commonest causes $[8,14,16-18]$. In the present 
study, the observed frequency of $21.7 \%$ of myelodysplastic syndrome (MDS) in pancytopenia is also slightly higher in comparison to few other studies where the same frequency ranged from $2 \%$ to $14 \%$ of pancytopenic cases [7,14,19]. As far as frequency of hypoplastic anemia is concerned our figure $(28.3 \%)$ is almost same as that of Jha, Sayami and Adhikari et al from Nepal (29\%) [16]. And this frequency of hypoplastic anemia amongst pancytopenic cases as observed by us is in consistent with the findings of few other studies where the frequency of hypoplastic anemia varied from $7.7 \%$ to $36 \%$ of pancytopenic cases [4,7,8,12-19]. In the present study we found only $4.4 \%$ cases of pancytopenia are due to hypersplenism, whereas Jain and Naniwadekar in their study in Maharashtra reported 29.2\% of cases of pancytopenia resulted from hypersplenism [20]. Such high frequency of hypersplenism as a cause of pancytopenia was not observed, to our knowledge, by any other investigators.

We did not come across infection as a cause of pancytopenia although in some of the studies as high as over $25 \%$ infection cases were found to be responsible for pancytopenia [7,9,17,20]. Likewise we have not found any storage disorder to be a cause for pancytopenia unlike in couple of other studies $[3,16]$. We investigated all the 26 cases of hypoplastic anemia for PNH with flowcytometric analysis of red cells for expression of CD55 and CD59. But no PNH clone was detected. This is in contrast with the findings in some studies where cases of PNH were found amongst hypoplastic anemia cases causing pancytopenia [21-26].

\section{Conclusion}

It is concluded that pancytopenia is often a manifestation of serious disease-processes and the commonest, in our population of this North-Eastern state of Tripura, being leukemia. Bone marrow aspiration/ imprint cytology and biopsy must be performed in all cases of pancytopenia to find out the cause in order to institute an early treatment.

Megaloblastic anemia due to vitamin- $\mathrm{B}_{12}$ deficiency is not uncommon even in a population with nonvegetarian food habits. So, further research on the issue in this population may be undertaken in future. It is also concluded that PNH amongst hypoplastic anemia cases is not common in the state of Tripura.

Acknowledgements: We acknowledge Indian Council of Medical Research (ICMR), New Delhi for funding the study-project (IRIS No. - 3076). We are grateful to Dr. Shikha Das, Professor \& Head, Department of Pathology, Agartala Govt. Medical College \& GB Pant Hospital for the administrative and moral support during the study. We also acknowledge Mrs. Shauli Sengupta, support staff and laboratory assistant for her sincere assistance in technical works.

Funding: Nil, Conflict of interest: None initiated, Permission from IRB: Yes

\section{References}

1. Frank F, Chesterman C, Pennington D and Rush B. de Gruchy's Clinical Hematology in Medical Practice. Pancytoenia; Aplastic Anaemia. $5^{\text {th }}$ ed. Delhi, Oxford University Press; 1989: pp.119-36.
2. Guinan EC, Shimamura A. Wintrobe's Clinical Hematology. In: Greer JP, Foerster J, Lukens JN, Rodgers GM, Paraskevas F, Glader B, editors. Acquired and inherited aplastic anemia syndromes. 11th ed. Philadelphia: Lippincott Williams and Wilkins; 2004. pp. 1397-419.

3. Gayathri BN, Rao KS. Pancytopenia: a clinico hematological study. J Lab Physicians. 2011 Jan;3(1): 15-20. doi: 10.4103/0974-2727.78555.

4. Desalphine M, Bagga PK, Gupta PK, Kataria AS. To evaluate the role of bone marrow aspiration and bone marrow biopsy in pancytopenia. J Clin Diagn Res. 2014 Nov;8(11):FC11-5. doi: 10.7860/JCDR/2014/ 9042. 5169. Epub 2014 Nov 20.

5. Tilak V, Jain R. Pancytopenia--a clinico-hematologic analysis of 77 cases. Indian J Pathol Microbiol. 1999 Oct;42(4):399-404.

6. Kumar R, Kalra SP, Kumar H, Anand AC, Madan H. Pancytopenia--a six year study. J Assoc Physicians India. 2001 Nov;49:1078-81.

7. Dasgupta S, Mandal PK, Chakrabarti S. Etiology of Pancytopenia: An Observation from a Referral Medical Institution of Eastern Region of India. J Lab Physicians. 2015 Jul-Dec; 7(2) : 90-5. doi: 10.4103 / 0974-2727. 163136.

8. Devi PM, Laishram RS, Sharma PS, Singh AM, Singh MK, Singh YM. Clinico-hematological profile of 
pancytopenia in Manipur, India. Kuwait Med J. 2008; 40:221-4.

9. Raphael V, Khonglah Y, Dey B ${ }^{1}$, Gogoi P, Bhuyan A. Pancytopenia: an etiological profile. Turk J Haematol. 2012 Mar;29(1):80-1. doi: 10.5505/tjh.2012. 98360. Epub 2012 Mar 5.

10. Lewis SM, Bain BJ, Bates I. Dacie and Lewis Practical Haematology. Basic haematological techniques; Preparation and staining methods for blood and bone marrow films; Erythrocyte and leucocyte cytochemistry - leukaemia classification. $9^{\text {th }}$ ed. Churchill Livingstone, Edinburgh 2001: pp 19-64 \& 269-95

11. Suvarna KS, Layton C and Bancroft JD . Bancroft's Theory and Practice of Histological Techniques. The hematoxylin and eosin (Ch.10). 7th ed. Churchill Livingstone, Philadelphia 2013: pp. 172-86.

12. Hunt BJ, Andrews V, Pettingale KW. The significance of pancytopenia in miliary tuberculosis. Postgrad Med J. 1987 Sep;63(743):801-4.

13. Niazi M, Raziq F. The incidence of underlying pathology in pancytopenia. An experience of 89 cases. J Postgr Med Inst 2004; 18(1): 76-9.

14. Basak TB, Talukder SI. Etiological Spectrum of Pancytopenia. Dinajpur Med Col J 2014; 7 (1):21-5.

15. Kumar DB, Raghupati AR, Clinicohematological analysis of pancytopenia Basic and Applied Pathology 2012 5:19-21.

16. Jha A, Sayami G, Adhikari RC, Panta AD, Jha R. Bone marrow examination in cases of pancytopenia. JNMA J Nepal Med Assoc.2008 Jan-Mar;47(169):12-7.

17.Memon S, Shaikh S, Nizamani MA. Etiological spectrum of pancytopenia based on bone marrow examination in children. J Coll Physicians Surg Pak. 2008 Mar;18(3):163-7. doi: 03.2008/JCPSP.163167.
18. Das Makheja K, Kumar Maheshwari B, Arain S, Kumar S, Kumari S, Vikash. The common causes leading to pancytopenia in patients presenting to tertiary care hospital. Pak J Med Sci. 2013 Sep;29(5):1108-11.

19. Khunger JM, Arulselvi S, Sharma U, Ranga S, Talib VH. Pancytopenia--a clinico haematological study of 200 cases. Indian J Pathol Microbiol. 2002 Jul;45 (3):375-9.

20. Jain A and Naniwadekar M. An etiological reappraisal of pancytopenia - largest series reported to date from a single tertiary care teaching hospital. BMC Hematol. 2013; 13: 10. Published online 2013 November 6. doi: 10.1186/2052-1839-13-10 .

21. Young NS, Maciejewski JP, Sloand E, Chen G, Zeng W, Risitano A, Miyazato A. The relationship of aplastic anemia and PNH. Int J Hematol. 2002 Aug;76 Suppl 2:168-72.

22. Kinoshita T, Inoue N. Relationship between aplastic anemia and paroxysmal nocturnal hemoglobinuria. Int $\mathbf{J}$ Hematol. 2002 Feb;75(2):117-22.

23. Parab RB. Paroxysmal nocturnal hemoglobinuria: a study of 17 cases. J Postgrad Med. 1990 Jan;36(1):23-6.

24. Gupta PK, Charan VD, Kumar H. PNH revisited: Clinical profile, laboratory diagnosis and follow-up. Indian J Pathol Microbiol. 2009 Jan-Mar;52(1):38-41.

25. Luzzatto L, Notaro R. Paroxysmal nocturnal hemoglobinuria. In : Handin RI, Lux SE, Stossel TP editors. Blood: Principles and Practice of Hematology. Philadelphia; Lippincott Williams \& Wilkins: 2003: pp. 318-32.

26. Naithani R, Mahapatra M, Dutta P, Kumar R, Pati HP, Choudhry VP. Paroxysmal nocturnal hemoglobinuria in childhood and adolescence--a retrospective analysis of 18 cases. Indian $\mathrm{J}$ Pediatr. 2008 Jun;75(6):575-8. doi: 10.1007/s12098-008-01119. Epub 2008 Aug 31.

\section{How to cite this article?}

Datta A, Banerjee A, Dasgupta A, Debbarma SK, Nath D. Diagnostic evaluation of pancytopenia - a prospective institutional study in North-East India.Int J Med Res Rev 2016;4(9):1602-1609.doi:10.17511/ijmrr. 2016.i09.15. 